\title{
Dental ceramics: a review of new materials and processing methods
}

\section{Lucas Hian da SILVA(a) \\ Erick de LIMA ${ }^{(b)}$ \\ Ranulfo Benedito de Paula \\ MIRANDA(b) \\ Stéphanie Soares FAVERO(b) \\ Ulrich LOHBAUER ${ }^{(c)}$ \\ Paulo Francisco CESAR ${ }^{(b)}$}

(a) Universidade Cidade de São Paulo - Unicid, School of Dentistry, São Paulo, SP, Brazil.

(b) Universidade de São Paulo - USP, School of Dentistry, Department of Biomaterials and

Oral Biology, São Paulo, SP, Brazil.

(c)Friedrich-Alexander-Universität ErlangenNürnberg - FAU, Dental Clinic 1, Erlangen, Germany.

Declaration of Interest: The authors certify that they have no commercial or associative interest that represents a conflict of interest in connection with the manuscript.

\section{Corresponding Author:}

Paulo Francisco Cesar

E-mail:paulofc@usp.br

https://doi.org/10.1590/1807-3107BOR-2017.vol31.0058

Submitted: May 15, 2017

Accepted for publication: May 22, 20117

Last revision: May 25, 2017

\begin{abstract}
The evolution of computerized systems for the production of dental restorations associated to the development of novel microstructures for ceramic materials has caused an important change in the clinical workflow for dentists and technicians, as well as in the treatment options offered to patients. New microstructures have also been developed by the industry in order to offer ceramic and composite materials with optimized properties, i.e., good mechanical properties, appropriate wear behavior and acceptable aesthetic characteristics. The objective of this literature review is to discuss the main advantages and disadvantages of the new ceramic systems and processing methods. The manuscript is divided in five parts: I) monolithic zirconia restorations; II) multilayered dental prostheses; III) new glass-ceramics; IV) polymer infiltrated ceramics; and V) novel processing technologies. Dental ceramics and processing technologies have evolved significantly in the past ten years, with most of the evolution being related to new microstructures and CAD-CAM methods. In addition, a trend towards the use of monolithic restorations has changed the way clinicians produce all-ceramic dental prostheses, since the more aesthetic multilayered restorations unfortunately are more prone to chipping or delamination. Composite materials processed via CAD-CAM have become an interesting option, as they have intermediate properties between ceramics and polymers and are more easily milled and polished.
\end{abstract}

Keywords: Ceramics; Dental Materials; Dental Porcelain; Computer-Aided Design; Composite Resins.

\section{Introduction}

The evolution of computerized systems for the production of dental restorations associated to the development of novel microstructures for ceramic materials has caused an important change in the clinical workflow for dentists and technicians, as well as in the treatment options offered to patients. One of the most important changes in this scenario was the introduction of monolithic restorations produced from high-strength ceramics, like zirconia. This concept per se is not new, since ceramic materials have been used for a relatively long time for the production of monolithic restorations, but it was only when zirconia started to be used to produce full-contour crowns that dentists and technicians became more confident to indicate a ceramic material for crowns and bridges in the posterior region. 
In fact, by offering monolithic prostheses, clinicians are able to overcome one of the major problems associated to multilayered restorations, which is the fracture of the low-strength veneering layer, usually made of a feldspathic dental ceramic. However, when using a monolithic zirconia restoration, other clinical problems may arise and need to be taken care of, such as wear of the antagonist dentition and matching the aesthetic characteristics of the natural dentition.

Due to the problem of chipping of the veneering layer, multilayered restorations have also evolved significantly in the past ten years. Most of the evolution of this system is associated to new processing techniques that aim at improving the final quality of the veneering material. Injection of the porcelain over the zirconia framework is an example of a new processing method that eliminates the porosity within the veneering layer and therefore improves its mechanical reliability. Other solutions have also been proposed, such as CAD-on and rapid layer techniques. The CAD-on technique involves the production of a stronger veneering layer based on lithium disilicate glass-ceramics sintered onto the zirconia framework using a fusion glass solder, and the rapid layer uses CAD-CAM (computer-aided design and computer-aided manufacturing) technology to mill the veneering layer that is afterwards cemented onto the zirconia framework. These new processing methods are relatively new and still need more clinical trials to prove their efficacy in relation to the traditional processing routes.

New microstructures have also been developed by the industry in order to offer ceramic and composite materials with optimized properties, i.e., good mechanical properties, appropriate wear behavior and acceptable aesthetic characteristics. Examples of these novel microstructures are lithium silicate glass-ceramics reinforced with zirconia and a composite constituted of a polymer-infiltrated ceramic. The latter uses an innovative processing technique in which a porous ceramic block is infiltrated with a UDMA-based polymer, as opposed to traditional resin composites produced by means of adding ceramic fillers to a polymer matrix. The main advantage of this material is that it is easier (faster) to be machined by CAD-CAM techniques, and its elastic modulus is closer to that of tooth tissues.
The objective of this literature review is to discuss the main advantages and disadvantages of the above mentioned new ceramic systems and processing methods. Clinical and laboratorial findings are thoroughly discussed in order to help clinicians and technicians to use these new technologies. The manuscript is divided in five parts: 1) monolithic zirconia restorations; 2) multilayered dental prostheses; 3) new glass-ceramics; 4) polymer infiltrated ceramics; and 5) novel processing technologies.

\section{Monolithic zirconia restorations}

Among polycrystalline ceramics, yttria stabilized tetragonal zirconia polycrystal (Y-TZP) for monolithic (full-contour) restorations has been developed more recently to overcome problems related to chipping of porcelain layers applied over zirconia. ${ }^{1,2}$ Zirconia exists in three different crystallographic forms: cubic, tetragonal and monoclinic phases. Y-TZP shows superior performance among dental ceramics due the high strength level of more than $1000 \mathrm{MPa}$ and its superior fracture toughness of 4 to $5 \mathrm{MPa} \cdot \mathrm{m}^{0.5}$. Especially the high fracture toughness is a consequence of a toughening mechanism related to the transformation of tetragonal grains into the monoclinic phase, which generates compression stresses around defects, hindering their catastrophic propagation. The microstructure of Y-TZPs for monolithic prostheses has been tailored to improve their translucency in comparison with conventional Y-TZP.

The better translucency of thenew zirconia materials has been achieved by means of microstructural modifications, like decrease in alumina content, increase in density, decrease in grain size, addition of cubic zirconia and decrease in the amount of impurities and structural defects. ${ }^{3,4}$ The size of the crystalline grain is the microstructural feature that is more closely related to the adjustment of the translucency of polycrystalline ceramics. The creation of ceramic materials with high translucency has been done in the past by means of increasing the grain size during sintering. ${ }^{5}$ Lager grains lead to a smaller number of grain boundaries, therefore reducing light scattering. For Y-TZP, it has been shown that larger grains are detrimental for both the mechanical properties and 
the stability of the tetragonal phase. Therefore, the translucency of zirconia cannot be achieved by means of increasing its grain size.

Another approach to produce a more translucent $\mathrm{Y}-\mathrm{TZP}$ is to decrease significantly the grain size. However, the grain size needs to be decreased until reaching a critical value that results in mitigation of the so-called birefringence phenomenon. ${ }^{4}$ Birefringence occurs in Y-TZP due to the large amount of tetragonal crystal phase ( $>90 \%$ ), which is a crystal that has different refractive indexes according to its crystallographic orientation in the microstructure. Such anisotropic behavior related to the variation in the refractive index causes significant light scattering, ${ }^{4,6}$ Another way to overcome these scattering effects is the use of cubic zirconia, which offers optical isotropic behavior, increasing the translucency.

For clinicians and dental technicians, monolithic zirconia restorations have become a very promising alternative, since the processing methods are simplified in comparison to traditional multilayered restorations, and therefore are less time consuming. From the biological standpoint, monolithic restorations made with zirconia allow clinicians to make much less invasive preparations, since this ceramic material has relatively high mechanical properties, especially when compared to veneering porcelains. In fact, important microstructural mechanisms, such as transformation toughening, hinder crack propagation through the restorations, and therefore, thinner structures can be constructed, preserving tooth tissues.

Although novel zirconia microstructures have higher translucency, the color of the final restoration is still limited to a whitish shade. Therefore, an important technological development for these materials is the coloring process that allows for a larger range of aesthetic possibilities. ${ }^{7}$ Laboratory studies indicated that the addition of coloring pigments to monolithic zirconia does not affect its flexural strength and translucency, however these results are related to specific coloring methodologies and cannot be generalized. ${ }^{8,9}$ Different techniques can be used to add color to zirconia restorations. One of them involves immersion of the material (dip coating) when it is at the presintered state in a solution containing different types of coloring dyes. This method has the disadvantage of resulting in a non-homogeneous final shade, since the pigments may penetrate only to a certain depth. ${ }^{10}$ Another coloring technique allows for the production of pre-colored zirconia pre-sintered blocks with a much more homogeneous shade. Pre-colored blocks of monolithic zirconia can be manufactured from a powder that is synthesized together with pigments or a powder which has been mixed with pigments. ${ }^{7}$

One factor that affects the translucency of dental ceramics is the restoration thickness. In general, the lower the thickness, the higher the translucency of a ceramic restoration, ${ }^{11,12}$ therefore, it is mandatory that translucency data is always reported accompanied by the material thickness. Considering the thickness of $0.5 \mathrm{~mm}$, traditional Y-TZP shows contrast ratio (CR) values that are higher (0.77) than those of monolithic Y-TZPs (0.57 to 0.62). ${ }^{13}$

In addition to the mechanical and optical properties, another important characteristic for the long-term success of a restoration is the wear of the antagonist enamel and the marginal adaptation. Fortunately, laboratory studies have shown that monolithic zirconia usually causes a rather comparable wear of the antagonists in comparison to other restorative ceramics, and this wear rate is within the physiological range reported in the literature. Some of these studies compared different surface finishing techniques for monolithic zirconia restorations, such as polishing versus glazing, and found that polished surfaces resulted in less enamel wear of the antagonist. $13,14,15,16$

It is needless to say that the high surface hardness of zirconia has a major influence on the antagonist wear and a perfect polish of any monolithic zirconia restoration is therefore very important. A clinical study evaluated the occlusal surface wear of monolithic zirconia crowns placed in premolars and molars. Impressions of the restorations were taken at the beginning of the trial and then 24 months later. Epoxy replicas were produced and both a qualitative (scanning electron microscopy) and a quantitative (optical profilometry) surface analyses were performed. The results showed that monolithic zirconia promoted an acceptable surface wear rate of the antagonist surface (natural enamel or ceramic material) after two years. ${ }^{17}$ Therefore, monolithic Y-TZP restorations with good surface finishing are not likely to wear significantly 
the antagonist element. However, following up these Y-TZP restorations is important because if there is a decrease in the surface quality, their wear potential will increase significantly.

The marginal adaptation of the monolithic restorations of Y-TZP improved over the years due to the evolution of CAD-CAM systems. Several of these systems and different materials had their adaptation evaluated: TZI, TZ Incoris (Dentsply-Sirona, Bensheim, Germany), CZ, Ceramill Zolid White (Amann Girrbach, Koblach, Austria), ZZ, Zenostar Zirconia (Wieland, Pforzheim, Germany), PZ, Prettau Zirconia (Zirkonzahn) and BZ, Bruxzir Solid Zirconia (Glidewell, Gais, Germany). Fortunately, all brands showed acceptable marginal discrepancy $n$, with the most advanced fiveaxis milling systems being superior to others. ${ }^{18}$

Another important issue regarding the use of monolithic zirconia for dental restorations is the ageing phenomenon, since these restorations are loaded in direct contact with the oral environment. Laboratory studies have evaluated the formation of the monoclinic crystalline phase and the flexural strength of different monolithic zirconia after ageing. Their results indicated that some brands are not susceptible to aging while others are more prone to tretragonal-to-monoclinic ( $\mathrm{t}-\mathrm{m})$ transformation. ${ }^{19,20}$ However, more studies are needed to evaluate this ageing phenomenon, since to date there is no scientific evidence from clinical studies linking the clinical failure of dental Y-TZP with this type of ageing.

The higher translucency of monolithic Y-TZPs expanded their indication for rehabilitations in aesthetic regions. However, extra caution is necessary before using this type of restoration indiscriminately, as there are only a few clinical follow-ups that evaluated monolithic zirconia crowns. One of these studies showed that out of 82 monolithic zirconia crowns installed in 60 patients, $6(7.3 \%)$ had complications after 3 years. The study showed that problems that affect this type of restoration are mostly related to loss of crown retention $(2.4 \%)$ and endodontic complications (4.9\%). Thus, this type of treatment is considered as promising, but clinical studies with longer follow-up times are still desirable. ${ }^{21}$

Another study collected data over five years from two United States laboratories. The laboratories provided insurance for restorations of monolithic zirconia that had problems, making new restorations without additional costs to the clinicians. The study included 39,827 restorations (all cemented in the natural dentition), which were classified into: anterior single crown (1,952); posterior single crown $(29,808)$; anterior fixed dental prostheses $(1,779)$ and posterior fixed dental prostheses $(6,288)$. Only the restorations that returned to laboratories to be replaced due to catastrophic fracture were considered as failures. The fracture rate $(\%)$ was 0.97 for anterior single crowns; 0.71 for posterior single crowns; 3.26 for the anterior fixed dental prostheses and 2.42 for the posterior fixed dental prostheses. The study concluded that restorations made with monolithic zirconia showed relatively low fracture rates. However, possibly some failed restorations may not have been counted, since the patient may have returned to another dentist or the dentist may have chosen another material to replace the restoration. ${ }^{22}$

\section{Multilayered dental prostheses}

Traditionally, fixed partial dentures (FPDs) produced with a metallic infrastructure and a ceramic veneering layer have excellent clinical performance, with studies showing an annual failure rate around $1 \%$ and a survival rate of $94 \%$ after 5 years of clinical follow-ups. ${ }^{23}$ Although these metal/ceramic bilayers are still considered the gold standard for FPDs, many studies have been carried out in order to achieve the same level of excellence using all-ceramic systems.

The lower biocompatibility ${ }^{24}$ and lower translucency of metals, when compared to ceramic materials, are the factors responsible for the use of ceramics as infrastructure materials in multilayered restorations. On the other hand, the relatively low fracture toughness of ceramic materials is a major limitation for their unrestricted use for prosthodontics solutions. This problem led to the development of a series of ceramic materials with high crystalline content, which are able to withstand the mechanical stresses generated during the application of chewing forces. Examples of such materials are alumina-based zirconia-reinforced glass infiltrated ceramic, polycrystalline alumina and Y-TZP. 
Among these ceramic materials, Y-TZP has gained remarkable popularity because of its excellent mechanical properties. ${ }^{25}$ However, materials with a high crystalline content still require a veneering layer constructed with a compatible porcelain in order to achieve a more favorable aesthetic result.

With respect to all-ceramic multilayered restorations, clinical follow-ups have reported little or no damage to the Y-TZP infrastructure during clinical use, however, chipping fractures of the veneering ceramic have been frequently reported. ${ }^{26}$ These failures compromise the restoration both functionally and aesthetically, requiring the replacement of the prosthetic piece when the fractured area is too large. The fracture of the veneering layer applied over Y-TZP frameworks has been associated with different factors, such as: a) design of the Y-TZP infrastructure, which should give support to the veneering layer, ${ }^{27} \mathrm{~b}$ ) relation between the thicknesses of the restoration layers (infrastructure and veneering ceramic, anatomical design), ${ }^{28}$ c) thermal residual stresses within the restoration, which are generated either during the cooling step at the sintering furnace ${ }^{29}$ or due to a certain mismatch of the coefficients of thermal expansion (CTE) of both layers and d) mechanical properties of the veneering ceramic.

Several methodologies for the application of the veneering layer on the ceramic infrastructure are available in the market and all of them aim at optimizing the resistance of this layer and, in some cases, to reduce the generation of residual thermal stresses. In the traditional or stratified processing technique, the manufacturer provides a ceramic powder and a modeling liquid (distilled water mixed with rheological modifiers). In order to produce the restoration, the Y-TZP framework receives the application of a mixture containing the veneering ceramic powder and the modeling liquid with the use of a brush. Several layers need to be applied in order to construct the desired dental element anatomy. This technique generates veneering layers susceptible to processing porosities and a series of intrinsic defects that can act as stress concentration areas, favoring the fracture of the restoration during chewing.

Another technique for the application of the veering layer is the so-called press-on method, in which the veneering material is applied on the ceramic infrastructure (made of Y-TZP) by means of a lost-wax in combination with a hot-pressing technique, resulting in a veneering layer with less pores and better mechanical behavior when compared to a veneering layer applied by the traditional technique. In this case, the veneering ceramic is provided in the form of pellets which are injected into a refractory mold (generated from the lost wax technique) containing the previously sintered Y-TZP framework. Stawarczyk et al. ${ }^{30}$ evaluated the load-bearing capacity of bilayered all-ceramic crowns as a function of different techniques for application of the veneering layer (injection of the Y-TZP versus the stratified technique) and concluded that crowns produced by means of injection of the veneering layer exhibited comparable and under certain configurations even superior fracture loads when compared to those made with the stratified technique.

Advances in CAD-CAM systems (computer aided design-computer aided manufacturing) in addition to an attempt to decrease the generation of residual thermal stresses in bilayered all-ceramic restorations have led to the development of new processing methods that involve milling of CAD-CAM blocks for both the framework and the veneering layer. In a further step, these layers are bonded with a resin cement or a fusion glass-ceramic. One of these systems is called the Rapid Layer Technique (Vita) and involves milling of both the Y-TZP infrastructure and the veneering layer, including a posterior cementation step using dual-cure resin-based luting agents. The other technique is called CAD-on (Ivoclar Vivadent, Schaan, Liechtenstein) and involves milling of the veneering layer from a lithium disilicate glass-ceramic CAD-CAM block. Lithium disilicate is a ceramic material that has much higher crystalline content compared to feldsphatic veneering ceramics and therefore presents higher mechanical properties. In the end of the process, both layers are bonded by means of a firing cycle that is carried out after the application of a fusion glass-ceramic (glass solder) between both layers.

One great advantage of restorations produced via CAD-CAM systems is the fact that the blocks used for production of the veneering layer are originated from optimized sintering procedures carried out by the manufacturer under ideal industrial conditions, 
which results in mechanically stronger blocks with less defects when compared to the veneering layers obtained by the previously described methodologies.

In 2012, one study ${ }^{31}$ evaluated the load-bearing capacity of all-ceramic crowns composed of Y-TZP veneered using the traditional technique, and crowns produced with the Cad-on system. The fracture load values were significantly different between these two groups, with mean values of $1,575 \mathrm{~N}$ for the crowns produced by the CAD-on system and $1,166 \mathrm{~N}$ for the crowns that received the veneering layer by the traditional technique. Another study ${ }^{32}$ used the CAD-on system to evaluate the effect of the bonding technique on the fracture resistance of molar crowns. In this study, specimens that had their layers bonded by a resin cement (Multilink Implant; Ivoclar Vivadent) showed a mean fracture resistance value lower than the value obtained for the group in which the components were bonded by means of the fusion glass-ceramic (IPS e.max Crystall Connect; Ivoclar Vivadent, Schaan, Liechtenstein). The mean values obtained in this study were $1,388 \pm 190 \mathrm{~N}$ for the fusion glass ceramic group versus 1,211 $\pm 158 \mathrm{~N}$ of the cemented group; however, this difference was not statistically significant.

Another in vitro study ${ }^{33}$ compared the fracture resistance of all-ceramic first molar crowns with Y-TZP infrastructures veneered with different techniques: layering (VM9; Vita, Bad Sachingen, Germany), press-on (IPS e.max ZirPress; Ivoclar vivadent, Schaan, Liechtenstein), and milling from CAD-CAM blocks (Lava ${ }^{\mathrm{TM}}$ DVS; 3M, Seefield, Germany) with posterior bonding using a fusion glass-ceramic. Multilayered restorations made from CAD-CAM blocks showed significantly higher fracture strength values $(6,242 \mathrm{~N})$ when compared to crowns made with the layering $(4,264 \mathrm{~N})$ and press-on $(5,071 \mathrm{~N})$ techniques.

\section{New glass-ceramics}

Nowadays, glass-ceramics are broadly used in prosthetic dentistry due to the continuous improvements of their mechanical properties associated to better microstructures and new processing methods. The adequate mechanical properties of these materials reflect in the good longevity of such dental restorations. ${ }^{34}$ The good aesthetic quality is another factor that greatly contributes to the attractiveness of glass-ceramics to clinicians ${ }^{35,36,37}$.

Since glass-ceramics started to be used in dentistry, ${ }^{38}$ materials with varied compositions have been developed; however, this class of materials gained popularity after the launching of lithium disilicate glass-ceramic in 1998 (IPS Empress ${ }^{\circledR}$ 2, Ivoclar Vivadent Ltda, Schaan, Liechtenstein, later on marketed as e.max $\left.{ }^{\circledR}\right)$. In comparison with leucite glass-ceramics, ${ }^{39}$ lithium disilicate-based materials have superior mechanical properties (Table 1), what expands their indication to the production of all-ceramic fixed partial dentures up to 3 elements. ${ }^{43}$

The first lithium disilicate glass-ceramic (based on the system $\mathrm{Li}_{2} \mathrm{O}: 2 \mathrm{SiO}_{2}$ ) was produced by melting a glass, which was then ground to form a powder that was used to make the so-called "blue" blocks or ingots with composition according to Table $2{ }^{44}$ Depending on the type of piece produced, whether it was a "blue" block for CAD-CAM system or the ingot for hot-pressed technique, the crystallization technique of this glass-ceramic changed. However, the crystallization process was similar in all situations.

Table 1. Mechanical properties for the traditional glassceramics in the market. ${ }^{40,41,42}$

\begin{tabular}{lccc}
\hline Material & $\begin{array}{c}\text { Flexural } \\
\text { strength } \\
(\mathrm{MPa})\end{array}$ & $\begin{array}{c}\text { Fracture } \\
\text { toughness } \\
\left(\mathrm{MPa} . \mathrm{m}^{1 / 2}\right)\end{array}$ & $\begin{array}{c}\text { Hardness } \\
(\mathrm{GPa})\end{array}$ \\
\hline Leucite glass-ceramic & 164 & 1.03 & 6.5 \\
Lithium disilicate glass-ceramic & 365 & 2.80 & 5.3 \\
\hline
\end{tabular}

Table 2. Composition of the glass-ceramic lithium disilicate IPS Empress ${ }^{\circledR} 2$ raw powder. ${ }^{44}$

\begin{tabular}{lc}
\hline Constituent & Weight \% \\
\hline $\mathrm{SiO}_{2}$ & $57-80$ \\
$\mathrm{Al}_{2} \mathrm{O}_{3}$ & $0-5$ \\
$\mathrm{La}_{2} \mathrm{O}_{3}$ & $0.1-6$ \\
$\mathrm{MgO}$ & $0-5$ \\
$\mathrm{ZnO}$ & $0-8$ \\
$\mathrm{~K}_{2} \mathrm{O}$ & $0-13$ \\
$\mathrm{Li}_{2} \mathrm{O}$ & $11-19$ \\
$\mathrm{P}_{2} \mathrm{O}_{5}$ & $0-11$ \\
Additives & $\sim 8$ \\
\hline
\end{tabular}


Briefly, the crystallization of the lithium disilicate is controlled by a heating cycle, in which lithium metasilicate $\left(\mathrm{Li}_{2} \mathrm{SiO}_{3}\right)$ reacts with the glassy phase $\left(\mathrm{SiO}_{2}\right)$ to originate lithium disilicate $\left(\mathrm{Li}_{2} \mathrm{Si}_{2} \mathrm{O}_{5}\right){ }^{45}$ Lithium metasilicate is nucleated from the base glass $\left(\mathrm{Li}_{3} \mathrm{PO}_{4}\right.$, amorphous) at the initial temperatures of the cycle. Later on, lithium disilicate glass-ceramics underwent some changes and gave rise to IPS e.max Lithium Disilicate (Ivoclar Vivadent Ltda., Barueri, Brazil), which has better mechanical properties, mostly due to the decrease in the size of the plateletshaped crystals (length varying from 2.0 to $3.0 \mu \mathrm{m}$ ) and the increase in interlocking among crystals. ${ }^{46,47}$

Despite the great acceptance and broad use of lithium disilicate glass-ceramics, the evolution of dental materials has attempted to suppress the remaining disadvantages of this ceramic system by means of the development of glass-ceramics reinforced with polycrystalline ceramics. These new glass-ceramics were designed to contain lithium silicate as the main crystalline phase in a vitreous matrix reinforced with zirconium dioxide crystals ( 10\%). ${ }^{48}$ When this material goes through the crystallization process, the nucleated lithium silicate crystals achieve a mean size $(0.5$ to $1 \mu \mathrm{m})$ that is up to 6 times smaller than that observed for lithium disilicate crystals present in lithium disilicate glass-ceramics. ${ }^{49}$ The formation of a smaller and finer crystalline phase occurs due to the presence of zirconia particles in the material, which acts as an additive influencing the crystallization by hindering crystal growth. ${ }^{50}$ A microstructure containing smaller crystals guarantees to this material mechanical properties similar to those observed for lithium disilicate ceramics. ${ }^{47}$ Additionally, as observed for traditional glass-ceramics, these new zirconium-reinforced lithium silicate materials maintain good optical properties, are easily milled in CAD-CAM machines and attain good surface finishing, as they still have a high amount of glass matrix. ${ }^{51}$

The two existing commercial examples of lithium silicate glass-ceramics are: a) Suprinity (Vita Zahnfabrik, Bad Sachingen, Germany), a material marketed in a partially crystallized state and that requires an additional thermal cycle in a furnace; and b) CELTRA Duo (Dentisply-Sirona, Bensheim, Germany), a material that is already in its final crystallization stage. Both materials have similar composition as shown in Table $3 .^{52}$
These novel zirconia-reinforced lithium silicate glass-ceramics have good mechanical properties associated with an excellent esthetic quality, thus being a valid alterative to lithium disilicate materials for prosthetic rehabilitations with high aesthetic demand. The main advantage of these materials is their timesaving ability for the production of dental restorations, since they are faster to be milled in CAD-CAM machines than lithium disilicate glass-ceramics ${ }^{53}$ and are already offered in their fully crystallized state (CELTRA Duo, Dentisply-Sirona, Bensheim, Germany) no furnace need) or need a very short crystallization cycle (Suprinity, Bad Sachingen, Germany). A particular advantage of the lithium silicate ceramic over the lithium disilicate version is the superior polishability due to the smaller crystal sizes in the microstructure.

\section{Polymer infiltrated ceramic networks (PICNs)}

In the last decades, the use of CAD-CAM systems in dentistry has increased exponentially, especially because of the general trends towards high productivity and aesthetics. ${ }^{54,55}$ Although CAD-CAM systems were developed initially for the production of ceramic restorations, pre-polymerized resin composites blocks have also been developed to be used with these systems. One of the first resin composites developed as a CAD-CAM block was Paradigm ${ }^{\mathrm{TM}}\left(3 \mathrm{M}^{\mathrm{TM}}\right.$, St Paul, USA), which was considered a fast-milling and wear-friendly alternative to the use of ceramics. However, problems commonly related to resin composite systems still need to be overcome, such as the reduced mechanical properties and poor wear resistance. ${ }^{54}$

Recently, a new material has been developed by Vita (VITA Zahnfabrik, Bad Säckingen, Germany) which is marketed as a polymer infiltrated in a porous ceramic,

Table 3. Composition of lithium silicate-based glass-ceramics. ${ }^{52}$

\begin{tabular}{lc}
\hline Constituent & Weight \% \\
\hline $\mathrm{SiO}_{2}$ & $56-64$ \\
$\mathrm{Al}_{2} \mathrm{O}_{3}$ & $1-4$ \\
$\mathrm{CeO}_{2}$ & $0-4$ \\
$\mathrm{ZrO}_{2}$ & $8-12$ \\
$\mathrm{~K}_{2} \mathrm{O}$ & $1-4$ \\
$\mathrm{Li}_{2} \mathrm{O}$ & $15-21$ \\
$\mathrm{P}_{2} \mathrm{O}_{5}$ & $3-8$ \\
\hline
\end{tabular}


generating an interpenetrating network (polymer infiltrated ceramic network, PICN). This new material was developed based on the glass infiltrated ceramic technology (In-Ceram System, Vita, Bad Sachingen, Germany), which was originally released by Vita in the 90 's. ${ }^{54}$ The infiltration of a resin into a porous ceramic preform is significantly different from the infiltration of a glass, since the final shrinkage of the polymer after infiltration is almost $5 \%$, i.e., much greater than the shrinkage experienced upon cooling of the infiltration glass, which is in the order of $1 \%{ }^{56}$

PICNs have the advantage of presenting an elastic modulus that is approximately $50 \%$ lower compared to feldspathic ceramics and hence closer to that of dentin, they are easier to mill and adjust, and also can be more easily repaired by composite resins. ${ }^{56}$ In comparison to dental porcelains, this new material has been proven to have lower elastic modulus and higher damage tolerance ${ }^{57}$ In 2013, the product Enamic (Vita, Bad Sachingen, Germany) was introduced for dental restorations. This PICN is based on initial sintering of a porcelain powder to approximately $70 \%$ of its full density, followed by infiltration with a monomer mixture. ${ }^{54,58,59}$ The material is considered a resin-ceramic composite material, composed of two interconnected networks: a dominant ceramic and a polymer. Recent publications showed that the polymeric part of this material is composed of urethane dimethacrylate (UDMA) and triethylene glycol dimethacrylate (TEGDMA) crosslinked polymers.$^{60}$ Compositional analyses of the dominant ceramic network revealed a major ceramic phase, composed (by weight) of $\mathrm{SiO}_{2}(58-63 \%), \mathrm{Al}_{2} \mathrm{O}_{3}$ (20-23\%), $\mathrm{Na}_{2} \mathrm{O}(9-11 \%), \mathrm{K}_{2} \mathrm{O}(4-6 \%), \mathrm{B}_{2} \mathrm{O} 3(0.5-2 \%), \mathrm{CaO}$ $(<1 \%)$ and $\mathrm{TiO}_{2}(<1 \%){ }^{61}$ Although being marketed as a polymer infiltrated ceramic, scientific analysis has shown that the inorganic matrix is rather an amorphous glass.

A recent publication ${ }^{62}$ reported that Enamic showed elastic modulus values similar to that reported by the manufacturer (around $30 \mathrm{GPa}$ ), however, the fracture toughness values measured in this investigation $\left(0.86 \mathrm{MPa}^{1 / 2}\right)$ were lower than that reported by the manufacturer $\left(1.5 \mathrm{MPa} \cdot \mathrm{m}^{1 / 2}\right)$. The fracture toughness value obtained for PICN was similar to that of the feldspathic ceramic evaluated. Therefore, the authors rejected the hypothesis that the presence of a polymer network would create toughening mechanisms in the microstructure of the material. In addition, this study showed that PICN had increased susceptibility to SCG compared to a feldsphatic ceramic. This raised the question if the polymer is susceptible to water permeation and degradation.

PICNs have positive properties related to both the ceramic and composites, with an interesting balance between elasticity and strength, being indicated for single crowns, inlays, onlays and veneers. The polymeric part has a strength below $30 \mathrm{MPa}$ and the ceramic network has a strength around $160 \mathrm{MPa}$, whereas the final PICN has strength of $135 \mathrm{MPa}$. As expected for a composite material, the properties are intermediate between those of ceramics and particle-filled resins. ${ }^{60,61,63}$

The elastic modulus of these materials is in the range of $30 \mathrm{GPa}$, which is half of that reported for conventional veneering ceramics but closer to what is usually reported for dentin (15-20 GPa) ${ }^{58,63}$ Typical ceramic materials have a higher elastic modulus values than PICN ${ }^{64}$. The Vickers hardness of human enamel ( $3.43 \pm 0.16 \mathrm{GPa})$ and PICN ( $3.31 \pm 0.11 \mathrm{GPa})$ are similar, ${ }^{54,65,66,67}$ and both are higher than the hardness reported for resin composites ( $0.73 \mathrm{GPa}$ to $1.60 \mathrm{GPa}){ }^{68,69}$ and lower than the hardness of zirconia $(13.94 \mathrm{GPa})^{70}$ and lithium disilicate glass ceramics (10.0 GPa to $11.31 \mathrm{GPa}) .^{71}$ The flexural strength of Enamic $(130 \mathrm{MPa})^{56}$ is lower than that of a reference lithium disilicate glassceramic material, IPS e.max (342 MPa). ${ }^{72}$ PICN has a higher tolerance to diamond bur grinding damage than other CAD/CAM and pressed materials. ${ }^{54,60,73}$ A study evaluated the damage tolerance of different dental materials and showed that the damage tolerance of PICN was higher when compared to other ceramics for CAD-CAM, like veneering ceramics. ${ }^{55,73}$

With respect to optical properties, the shrinkage of the curing resin results in interfacial stresses occurring between the ceramic framework and the polymer resulting in debonding and leading to a higher opacity because of the gaps developed at the interface. The selection of resin, the application of high pressure during the curing phase, and the silanization process enhanced bonding and helped overcoming the aesthetic problems by increasing the translucency of the material. ${ }^{64}$ However, Enamic has been shown to be less translucent than IPS e.max or Lava Ultimate (3M ESPE, St Paul, USA). ${ }^{74}$ Previous 
works have also shown that the surface of PICN is not as glossy as those obtained for IPS e.max or Lava Ultimate. Nevertheless, the stain resistance of PICN was superior than that measured for Lava Ultimate and inferior than that reported for IPS e.max..$^{56,75}$

Clinical simulations show promising lifetime results for PICN. A chewing simulation of five years demonstrated that none of the Enamic crowns failed, while six IPS e.max CAD had minor cracking and twelve Vita Mark II restorations revealed significant crack failures. ${ }^{64}$ In a cyclic fatigue experiment of 500,000 cycles, Enamic performed as well as a lithium disilicate glass-ceramic. ${ }^{58,76}$ Based on the reduced elastic modulus of Enamic, this material is especially indicated for prosthetic treatments on stiff implants. Due to the inferior optical properties, PICNs are more suitable in the molar than in the anterior region.

\section{Novel processing technologies}

CAD-CAM refers to a computer system that is used to both design and manufacture a dental restoration. CAD technology uses a software to define the shape and dimensions of the restoration, while CAM technology takes the designed model to a computer numeric control (CNC) machine to manufacture the restoration, usually from a block made of a dental material (subtractive manufacturing).

Currently, the production of metal-free restorations using polycrystalline ceramic infrastructures (e.g., Y-TZP) depends on the use of the CAD-CAM systems. ${ }^{77}$ The introduction of CAD-CAM milling systems for the production of restorations with these polycrystalline ceramics allowed their use in prosthetic restorations with greater reliability, since the only manufacturing technique available in the past was slip-casting, which resulted in a greater number of defects and cracks in the microstructure of the final restorations. ${ }^{78}$

CAD-CAM systems have been used in Dentistry for almost 30 years, ${ }^{79}$ and during this period different machines have been launched, as these systems are constantly evolving and producing restorations with much better adaptation. ${ }^{80,81}$ Moreover, the evolution of CAD-CAM system have allowed their use to produce restorations with other materials such as veneering ceramics, resin composites and metal alloys. ${ }^{77,82}$
Among dental CAD-CAM systems, there are two types of techniques for producing restorations. The first one is the machining of the prosthetic restoration from a block of the sintered material, while the second consists of machining a block in a partially sintered state with subsequent final sintering in a specific furnace. Both techniques are used in dentistry and each of them have their advantages and disadvantages.

Machining a block of sintered material provides the restoration with a greater precision of its contours and shape in addition to saving clinical time, since the restoration does not require an additional heat treatment. However, when machining a material with high strength like polycrystalline ceramics, both the wear of the machining unit tools and the machining time are very high. Also, machining brittle materials such as dental ceramics can lead to the formation of microcracks and surface defects..$^{83}$ On the other hand, when the restoration is produced from a partially sintered block, there is the advantage of promoting healing of machining microcracks during the subsequent sintering process. ${ }^{84}$ This processing technique is expected to have a shorter machining time for a less dense material, but one must keep in mind that the final sintering will promote dimensional changes due to shrinkage, which may lead to prosthetic restoration misfit. ${ }^{85}$

Although the CAD-CAM systems described above are already well established in the dental market, they present a major drawback related to the great waste of material upon machining. The waste corresponds to approximately $90 \%$ of the prefabricated block for a typical restoration ${ }^{86}$ and leftovers from these dental restorations are not reusable. Therefore, new technologies have been developed to overcome this problem. Some of them produce the restoration by means of adding layers instead of grinding pre-fabricated blocks (additive manufacturing).

Addition CAD-CAM systems, also called "solid free-form fabrication", are still a focus of research and development for polycrystalline ceramic materials and there are three techniques that have stood out recently. ${ }^{86,87,88,89,90}$ These techniques are: 1) Selective Laser Sintering or Melting, 2) Direct 3D Printing and 3) Stereolithography.

The Selective Laser Sintering or Melting is an already well-established technique for metal alloys, 
but is still in development for polycrystalline ceramics (BEGO Medifacturing ${ }^{\circledR}$ System, BEGO Medical $\mathrm{GmbH}$, Bremen, Germany). In this technique, the laser beam sinters thin layers of a ceramic from a container filled with powder to create a single coping or framework, in which each layer represents a cross section of the CAD model..$^{86}$ Direct 3D Printing is similar to a traditional inkjet printer, performing the direct printing of a ceramic suspension, allowing the generation of dense green bodies with high resolution, and producing complex shapes..$^{90,91}$

Stereolithography is frequently used nowadays, and has already evolved enough to allow production of more complex ceramic pieces, whereas the previously mentioned techniques are in the early development stage for dental applications. Stereolithography is similar to 3D printing, however it makes use of a suspension containing ceramic particles mixed with a resin components (acrylates or epoxy monomers). ${ }^{87,88}$ This resin part is polymerized during printing to shape the solid object and is subsequently removed during the ceramic sintering process. The great advantage associated with all additive techniques is that they provide minimal or no material waste. One still existing disadvantage of all additive methods to date is the rough surface quality and the poor fit or marginal precision.

Considering the mentioned additive methods, Direct 3D Printing is the technique that stands out,

\section{References}

\footnotetext{
1. Marchack BW, Sato S, Marchack CB, White SN. Complete and partial contour zirconia designs for crowns and fixed dental prostheses: a clinical report. J Prosthet Dent. 2011;106(3):145-52. https://doi.org/10.1016/S0022-3913(11)60112-1

2. Schley JS, Heussen N, Reich S, Fischer J, Haselhuhn K, Wolfart S. Survival probability of zirconiabased fixed dental prostheses up to $5 \mathrm{yr}$ : a systematic review of the literature. Eur J Oral Sci. 2010;118(5):443-50. https://doi.org/10.1111/j.1600-0722.2010.00767.x

3. Zhang H, Li Z, Kim B-N, Morita K, Yoshida H, Hiraga $\mathrm{K}$ et al. Effect of alumina dopant on transparency of tetragonal zirconia. J Nanomater. 2012;2012:ID269064. https://doi.org/10.1155/2012/269064
}

as the equipment is relatively more accessible and allows for the production of a dense green body ready for sintering. In $2009,{ }^{91}$ using a modified inkjet printer, a zirconia crown was manufactured with sufficient mechanical properties to be used in the oral cavity. The impression of the posterior dental crown was performed using a cartridge filled with a $27 \mathrm{vol} \%$ solid content of zirconia-based ceramic suspension. Variations of the Direct 3D Printing technique have also been studied, the so-called "Robocasting". 89 Both techniques are very similar, differing only in the way the deposition of the ceramic suspension is made. Robocasting uses extruded filaments instead of ejected droplets to produce the object.

\section{Conclusion}

Dental ceramics and processing technologies have evolved significantly in the past ten years, with most of the evolution being related to new microstructures and CAD-CAM methods. Also, a trend towards the use of monolithic restorations has changed the way clinicians produce all-ceramic dental prostheses, since the more aesthetic multilayered restorations unfortunately are more prone to chipping or delamination. Composite materials processed via CAD-CAM have become an interesting option, as they have intermediate properties between ceramics and polymers and are more easily milled and polished.
4. Zhang Y. Making yttria-stabilized tetragonal zirconia translucent. Dent Mater. 2014;30(10):1195-203. https://doi.org/10.1016/j.dental.2014.08.375

5. Cheng J, Agrawal D, Zhang Y, Roy R. Microwave sintering of transparent alumina. Mater Lett. 2002;56(4):587-92. https://doi.org/10.1016/S0167-577X(02)00557-8

6. Klimke J, Trunec M, Krell A. Transparent tetragonal yttria-stabilized zirconia ceramics: influence of scattering caused by birefringence. J Am Ceram Soc. 2011;94(6):1850-8 https://doi.org/10.1111/j.1551-2916.2010.04322.x

7. Kim HK, Kim SH. Optical properties of pre-colored dental monolithic zirconia ceramics. J Dent. 2016;55:75-81. https://doi.org/10.1016/i.jdent.2016.10.001 
8. Sedda M, Vichi A, Carrabba M, Capperucci A, Louca C, Ferrari M. Influence of coloring procedure on flexural resistance of zirconia blocks. J Prosthet Dent. 2015;114(1):98-102. https://doi.org/10.1016/i.prosdent.2015.02.001

9. Kim HK, Kim SH. Effect of the number of coloring liquid applications on the optical properties of monolithic zirconia. Dent Mater. 2014;30(9):e229-37. https://doi.org/10.1016/i.dental.2014.04.008

10. Rinke $S$, Fischer $C$. Range of indications for translucent zirconia modifications: clinical and technical aspects. Quintessence Int. 2013;44(8):557-66. https://doi.org/10.3290/i.qi.a29937

11. Kim HK, Kim SH, Lee JB, Han JS, Yeo IS, Ha SR. Effect of the amount of thickness reduction on color and translucency of dental monolithic zirconia ceramics. J Adv Prosthodont. 2016;8(1):37-42. https://doi.org/10.4047/jap.2016.8.1.37

12. Antonson SA, Anusavice KJ. Contrast ratio of veneering and core ceramics as a function of thickness. Int J Prosthodont. 2001;14(4):316-20.

13. Stawarczyk B, Frevert K, Ender A, Roos M, Sener B, Wimmer T. Comparison of four monolithic zirconia materials with conventional ones: contrast ratio, grain size, four-point flexural strength and two-body wear. J Mech Behav Biomed Mater. 2016;59:128-38. https://doi.org/10.1016/i.jmbbm.2015.11.040

14. Lawson NC, Janyavula S, Syklawer S, McLaren EA, Burgess JO. Wear of enamel opposing zirconia and lithium disilicate after adjustment, polishing and glazing. J Dent. 2014;42(12):1586-91. https://doi.org/10.1016/i.jdent.2014.09.008

15. Park JH, Park S, Lee K, Yun KD, Lim HP. Antagonist wear of three CAD/CAM anatomic contour zirconia ceramics. J Prosthet Dent. 2014;111(1):20-9. https://doi.org/10.1016/i.prosdent.2013.06.002

16. Jung YS, Lee JW, Choi YJ, Ahn JS, Shin SW, Huh JB. A study on the in-vitro wear of the natural tooth structure by opposing zirconia or dental porcelain. J Adv Prosthodont. 2010;2(3):111-15. https://doi.org/10.4047/jap.2010.2.3.111

17. Lohbaver $U$, Reich S. Antagonist wear of monolithic zirconia crowns after 2 years. Clin Oral Investig. 2017;21(4):1165-72. https://doi.org/10.1007/s00784-016-1872-6

18. Hamza TA, Sherif RM. In vitro evaluation of marginal discrepancy of monolithic zirconia restorations fabricated with different CAD-CAM systems. J Prosthet Dent. 2017;117(6):762-6. http://dx.doi.org/10.1016/i.prosdent.2016.09.011

19. Flinn BD, Raigrodski AJ, Mancl LA, Toivola R, Kuykendall T. Influence of aging on flexural strength of translucent zirconia for monolithic restorations. J Prosthet Dent. 2017;117(2):302-9. https://doi.org/10.1016/i.prosdent.2016.06.010

20. Pereira G, Silvestri T, Camargo R, Rippe MP, Amaral M, Kleverlaan $\mathrm{CJ}$ et al. Mechanical behavior of a Y-TZP ceramic for monolithic restorations: effect of grinding and low-temperature aging. Mater Sci Eng C. 2016;63:70-7. https://doi.org/10.1016/j.msec.2016.02.049

21. Bömicke W, Rammelsberg P, Stober T, Schmitter M. Short-term prospective clinical evaluation of monolithic and partially veneered zirconia single crowns. J Esthet Restor Dent. 2017;29(1):22-30. https://doi.org/10.1111/jerd.12270

22. Sulaiman TA, Abdulmajeed AA, Donovan TE, Cooper LF, Walter R. Fracture rate of monolithic zirconia restorations up to 5 years: a dental laboratory survey. Prosthet Dent. 2016,116(3):436-9. https://doi.org/10.1016/i.prosdent.2016.01.033

23. Pjetursson BE, Sailer I, Makarov NA, Zwahlen M, Thoma DS. All-ceramic or metal-ceramic tooth-supported fixed dental prostheses (FDPs)? A systematic review of the survival and complication rates. Partm: multiple-unit FDPs. Dent Mater. 2015;31(6):624-39. https://doi.org/10.1016/i.dental.2015.02.013

24. Lucas LC, Lemons JE. Biodegradation of restorative metallic systems. Adv Dent Res. 1992;6(1):32-7. https://doi.org/10.1177/08959374920060011301

25. Piconi C, Maccauro G. Zirconia as a ceramic biomaterial. Biomaterials. 1999;20(1):1-25. https://doi.org/10.1016/S0142-9612(98)00010-6

26. Sailer I, Fehér A, Filser F, Gauckler LJ, Lüthy H, Hämmerle CH. Five-year clinical results of zirconia frameworks for posterior fixed partial dentures. Int J Prosthodont. 2007;20(4):383-8.

27. Guess PC, Bonfante EA, Silva NR, Coelho PG, Thompson VP. Effect of core design and veneering technique on damage and reliability of Y-TZP-supported crowns. Dent Mater. 2013;29(3):307-16. https://doi.org/10.1016/i.dental.2012.11.012

28. White SN, Miklus VG, McLaren EA, Lang LA, Caputo AA. Flexural strength of a layered zirconia and porcelain dental all-ceramic system. J Prosthet Dent. 2005;94(2):125-31. https://doi.org/10.1016/i.prosdent.2005.05.007

29. Al-Amleh B, Neil Waddell J, Lyons K, Swain MV. Influence of veneering porcelain thickness and cooling rate on residual stresses in zirconia molar crowns. Dent Mater. 2014;30(3):271-80. https://doi.org/10.1016/i.dental.2013.11.011

30. Stawarczyk B, Ozcan M, Roos M, Trottmann A, Sailer I, H6ammerle $\mathrm{CH}$. Load-bearing capacity and failure types of anterior zirconia crowns veneered with overpressing and layering techniques. Dent Mater. 2011;27(10):1045-53. https://doi.org/10.1016/i.dental.2011.07.006

31. Schmitter M, Mueller D, Rues S. Chipping behaviour of all-ceramic crowns with zirconia framework and CAD/CAM manufactured veneer. J Dent. 2012;40(2):154-62. https://doi.org/10.1016/i.jdent.2011.12.007

32. Schmitter M, Schweiger M, Mueller D, Rues S. Effect on in vitro fracture resistance of the technique used to attach lithium disilicate ceramic veneer to zirconia frameworks. Dent Mater. 2014;30(2):122-30. https://doi.org/10.1016/i.dental.2013.10.008

33. Choi YS, Kim SH, Lee JB, Han JS, Yeo IS. In vitro evaluation of fracture strength of zirconia restoration veneered with various ceramic materials. J Adv Prosthodont. 2012;4(3):162-9. https://doi.org/10.4047/jap.2012.4.3.162 
34. Anusavice KJ, Kakar K, Ferree N. Which mechanical and physical testing methods are relevant for predicting the clinical performance of ceramic-based dental prostheses? Clin Oral Implants Res. 2007;18 Suppl 3:218-31. https://doi.org/10.1111/j.1600-0501.2007.01460.x

35. Höland W, Beall GH. Glass ceramic technology. 2nd ed. Hoboken: John Wiley \& Sons; 2012.

36. Höland W, Rheinberger V, Apel E, Hoen C, Höland M, Dommann A et al. Clinical applications of glass-ceramics in dentistry. J Mater Sci Mater Med. 2006;17(11):1037-42. https://doi.org/10.1007/s10856-006-0441-y

37. Ritzberger C, Apel E, Höland W, Peschke A, Rheinberger VM. Properties and clinical application of three types of dental glass-ceramics and ceramics for CAD-CAM technologies. Mater. 2010;3(6):3700-13. https://doi.org/10.3390/ ma3063700

38. MacCulloch WT. Advances in dental ceramics. Br Dent J. 1968;124(8):361-5.

39. Höland W, Schweiger M, Frank M, Rheinberger V. A comparison of the microstructure and properties of the IPS Empress 2 and the IPS Empress glass-ceramics. J Biomed Mater Res. 2000;53(4):297-303. https:// doi.org/10.1002/1097-4636(2000)53:4<297::AIDJBM3 $>3.0 . C O ; 2-G$

40. Lin WS, Ercoli C, Feng C, Morton D. The effect of core material, veneering porcelain, and fabrication technique on the biaxial flexural strength and weibull analysis of selected dental ceramics. J Prosthodont. 2012;21(5):353-62. https://doi.org/10.1111/j.1532-849X.2012.00845.x

41. Quinn JB, Sundar V, Lloyd IK. Influence of microstructure and chemistry on the fracture toughness of dental ceramics. Dent Mater. 2003;19(7):603-11. https://doi.org/10.1016/S0109-5641(03)00002-2

42. Guazzato M, Albakry M, Ringer SP, Swain MV. Strength, fracture toughness and microstructure of a selection of all-ceramic materials. Part I. Pressable and alumina glass-infiltrated ceramics. Dent Mater. 2004;20(5):441-8. https://doi.org/10.1016/i.dental.2003.05.003

43. Kern M, Sasse M, Wolfart S. Ten-year outcome of three-unit fixed dental prostheses made from monolithic lithium disilicate ceramic. J Am Dent Assoc. 2012;143(3):234-40. https://doi.org/10.14219/jada.archive.2012.0147

44. Schweiger M, Höland W, Frank M, Drescher H, Rheinberger V. IPS Empress 2: a new pressable high-strength glass-ceramic for esthetic all-ceramic restorations. Quintessence Dent Technol. 1999;22:143-51.

45. Ritzberger C, Schweiger M, Höland W. Principles of crystal phase formation in Ivoclar Vivadent glass-ceramics for dental restorations. J Non Cryst Solids. 2016;432 Part A:137-42. https://doi.org/10.1016/i.jnoncrysol.2015.04.034

46. Kang SH, Chang J, Son HH. Flexural strength and microstructure of two lithium disilicate glass ceramics for CAD/CAM restoration in the dental clinic. Restor Dent Endod. 2013;38(3):134-40. https://doi.org/10.5395/rde.2013.38.3.134
47. Wendler M, Belli R, Petschelt A, Mevec D, Harrer W, Lube $T$ et al. Chairside CAD/CAM materials. Part 2: flexural strength testing. Dent Mater. 2017;33(1):99-109. https://doi.org/10.1016/i.dental.2016.10.008

48. Rinke S, Pabel A-K, diger M, Ziebolz D. Chairside Fabrication of an all-ceramic partial crown using a zirconia-reinforced lithium silicate ceramic. Case Rep Dent. 2016;2016:ID1354186. http://dx.doi.org/10.1155/2016/1354186

49. Belli R, Wendler $M$, de Ligny $D$, Cicconi MR, Petschelt A, Peterlik $\mathrm{H}$ et al. Chairside CAD/CAM materials. Part 1: measurement of elastic constants and microstructural characterization. Dent Mater. 2017;33(1):84-98. https://doi.org/10.1016/j.dental.2016.10.009

50. Apel E, van'† Hoen C, Rheinberger V, Höland W. Influence of $\mathrm{ZrO} 2$ on the crystallization and properties of lithium disilicate glass-ceramics derived from a multi-component system. J Eur Ceram Soc. 2007;27(2-3):1571-77. https://doi.org/10.1016/i.jeurceramsoc.2006.04.103

51. Krüger S, Deubener J, Ritzberger C, Höland W. Nucleation kinetics of lithium metasilicate in $\mathrm{ZrO} 2$-bearing lithium disilicate glasses for dental application. Int J Appl Glass Sci 2013;4(1):9-19. https://doi.org/10.1111/ijag.12011

52. Gracis S, Thompson VP, Ferencz JL, Silva NR, Bonfante EA. A new classification system for all-ceramic and ceramic-like restorative materials. Int J Prosthodont. 2015;28(3):227-35. https://doi.org/10.11607/ijp.4244

53. Rinke S, Pabel AK, Rodiger M, Ziebolz D. Chairside Fabrication of an all-ceramic partial crown using a zirconia-reinforced lithium silicate ceramic. Case Rep Dent. 2016;2016:ID1354186. http://dx.doi.org/10.1155/2016/1354186

54. He LH, Swain M. A novel polymer infiltrated ceramic dental material. Dent Mater. 2011;27(6):527-34. https://doi.org/10.1016/i.dental.2011.02.002

55. Coldea A, Fischer J, Swain MV, Thiel N. Damage tolerance of indirect restorative materials (including PICN) after simulated bur adjustments. Dent Mater. 2015;31(6):684-94. https://doi.org/10.1016/i.dental.2015.03.007

56. Chirumamilla G, Goldstein CE, Lawson NC. A 2-year retrospective clinical study of enamic crowns performed in a private practice setting. J Esthet Restor Dent. 2016;28(4):231-7. https://doi.org/10.1111/jerd.12206

57. Coldea A, Swain MV, Thiel N. In-vitro strength degradation of dental ceramics and novel PICN material by sharp indentation. J Mech Behav Biomed Mater. 2013;26:34-42. https://doi.org/10.1016/i.jmbbm.2013.05.004

58. Denry I, Kelly JR. Emerging ceramic-based materials for dentistry. J Dent Res. 2014;93(12):1235-42. https://doi.org/10.1177/0022034514553627

59. Ruse ND, Sadoun MJ. Resin-composite blocks for dental CAD/CAM applications. J Dent Res. 2014;93(12):1232-4. https://doi.org/10.1177/0022034514553976

60. Coldea A, Swain MV, Thiel N. Mechanical properties of polymer-infiltrated-ceramic-network materials. Dent Mater. 2013;29(4):419-26. https://doi.org/10.1016/i.dental.2013.01.002 
61. Shetty R, Shenoy K, Dandekeri S, Suhaim KS, Ragher M, Francis J. Resin-matrix ceramics: an overview. Int J Rec Sci Res. 2015;6(11):7414-17.

62. Ramos NC, Campos TMB, Paz IS, Machado JPB, Bottino MA, Cesar PF et al. Microstructure characterization and SCG of newly engineered dental ceramics. Dent Mater. 2016;32(7):870-8. https://doi.org/10.1016/j.dental.2016.03.018

63. Della Bona A, Corazza PH, Zhang Y.

Characterization of a polymer-infiltrated ceramicnetwork material. Dent Mater. 2014;30(5):564-9. https://doi.org/10.1016/i.dental.2014.02.019

64. Swain MV, Coldea A, Bilkhair A, Guess PC. Interpenetrating network ceramic-resin composite dental restorative materials. Dent Mater. 2016;32(1):34-42. https://doi.org/10.1016/i.dental.2015.09.009

65. Padmanabhan SK, Balakrishnan A, Chu MC, Kim TN, Cho SJ. Micro-indentation fracture behavior of human enamel. Dent Mater. 2010;26(1):100-04. https://doi.org/10.1016/j.dental.2009.07.015

66. Albero A, Pascual A, Camps I, Grau-Benitez M. Comparative characterization of a novel cad-cam polymer-infiltrated-ceramic-network. J Clin Exp Dent. 2015;7(4):e495-500. https://doi.org/10.4317/jced.52521

67. Min J, Arola DD, Yu D, Yu P, Zhang Q, $\mathrm{Yu} \mathrm{H}$ et al. Comparison of human enamel and polymer-infiltrated-ceramic-network material "ENAMIC" through micro-and nano-mechanical testing. Ceram Int. 2016;42(9):10631-7. https://doi.org/10.1016/j.ceramint.2016.03.160

68. El-Safty S, Akhtar R, Silikas N, Watts DC. Nanomechanical properties of dental resin-composites. Dent Mater. 2012;28(12):1292-300. https://doi.org/10.1016/j.dental.2012.09.007

69. Xu HH, Smith DT, Schumacher GE, Eichmiller FC, Antonucci JM. Indentation modulus and hardness of whisker-reinforced heat-cured dental resin composites. Dent Mater. 2000;16(4):248-54. https://doi.org/10.1016/S0109-5641(00)00014-2

70. Zhang Y, Allahkarami M, Hanan JC. Measuring residual stress in ceramic zirconia-porcelain dental crowns by nanoindentation. J Mech Behav Biomed Mater. 2012;6:120-7. https://doi.org/10.1016/i.jmbbm.2011.11.006

71. Smith CM, Jiang D, Gong J, Yin L. Determination of the mechanical behavior of lithium disilicate glass ceramics by nanoindentation \& scanning probe microscopy. Mater Chem Phys. 2014;148(3):1036-44. https://doi.org/10.1016/i.matchemphys.2014.09.015

72. Leung BT, Tsoi JK, Matinlinna JP, Pow EH. Comparison of mechanical properties of three machinable ceramics with an experimental fluorophlogopite glass ceramic. J Prosthet Dent. 2015;114(3):440-6. https://doi.org/10.1016/i.prosdent.2015.02.024

73. Tsitrou EA, Northeast SE, Noort R. Brittleness index of machinable dental materials and its relation to the marginal chipping factor. J Dent. 2007;35(12):897-902. https://doi.org/10.1016/i.jdent.2007.07.002
74. Awad D, Stawarczyk B, Liebermann A, Ilie N. Translucency of esthetic dental restorative CAD/CAM materials and composite resins with respect to thickness and surface roughness. J Prosthet Dent. 2015;113(6):534-40. https://doi.org/10.1016/i.prosdent.2014.12.003

75. Lawson NC, Burgess JO. Gloss and stain resistance of ceramic-polymer CAD/CAM restorative blocks. J Esthet Restor Dent. 2016;28 Suppl 1:S40-5. https://doi.org/10.1111/jerd.12166

76. Kelly JR, Rungruanganunt $P$, Hunter B, Vailati F. Development of a clinically validated bulk failure test for ceramic crowns. J Prosthet Dent. 2010;104(4):228-38. https://doi.org/10.1016/S0022-3913(10)60129-1

77. Raigrodski AJ. Contemporary materials and technologies for all-ceramic fixed partial dentures: a review of the literature. J Prosthet Dent. 2004;92(6):557-62. https://doi.org/10.1016/i.prosdent.2004.09.015

78. Anusavice KJ. Reducing the failure potential of ceramic-based restorations. Part 2: ceramic inlays, crowns, veneers, and bridges. Gen Dent. 1997;45(1):30-5.

79. Duret F, Blouin JL, Duret B. CAD-CAM in dentistry. J Am Dent Assoc. 1988;117(6):715-20. https://doi.org/10.14219/jada.archive.1988.0096

80. Liu PR. A panorama of dental CAD/CAM restorative systems. Compend Contin Educ Dent. 2005;26(7):507-10.

81. Miyazaki T, Hotta Y, Kunii J, Kuriyama S, Tamaki Y. A review of dental CAD/CAM: current status and future perspectives from 20 years of experience. Dent Mater J. 2009;28(1):44-56. https://doi.org/10.4012/dmi.28.44

82. Stansbury JW, Idacavage MJ. 3D printing with polymers: challenges among expanding options and opportunities. Dent Mater. 2016;32(1):54-64. https://doi.org/10.1016/i.dental.2015.09.018

83. Huang $\mathrm{H}$. Machining characteristics and surface integrity of yttria stabilized tetragonal zirconia in high speed deep grinding. Mater Sci Eng A. 2003;345(1-2):155-63. https://doi.org/10.1016/S0921-5093(02)00466-5

84. Wang $H$, Aboushelib MN, Feilzer AJ. Strength influencing variables on CAD/CAM zirconia frameworks. Dent Mater. 2008;24(5):633-8. https://doi.org/10.1016/j.dental.2007.06.030

85. Kohorst P, Junghanns J, Dittmer MP, Borchers $L$, Stiesch M. Different CAD/CAM-processing routes for zirconia restorations: influence on fitting accuracy. Clin Oral Investig. 2011;15(4):527-36. https://doi.org/10.1007/s00784-010-0415-9

86. Strub JR, Rekow ED, Witkowski S. Computer-aided design and fabrication of dental restorations: current systems and future possibilities. J Am Dent Assoc. 2006;137(9):1289-96. https://doi.org/10.14219/jada.archive.2006.0389

87. Chartier T, Chaput C, Doreau F, Loiseau M. Stereolithography of structural complex ceramic parts. J Mater Sci. 2002;37(15):3141-47. https://doi.org/10.1023/A:1016102210277 
- Dental ceramics: a review of new materials and processing methods

88. Doreau F, Chaput C, Chartier T. Stereolithography for manufacturing ceramic parts. Adv Eng Mater. 2000;2(8):493-6. https://doi.org/10.1002/15272648(200008)2:8<493::AID-ADEM493>3.0.CO;2-C

89. Silva NR, Witek L, Coelho PG, Thompson VP, Rekow ED, Smay J. Additive CAD/CAM process for dental prostheses. J Prosthodont. 2011;20(2):93-6. https://doi.org/10.1111/j.1532-849X.2010.00623.x
90. Özkol E, Zhang W, Ebert J, Telle R. Potentials of the "Direct inkjet printing" method for manufacturing 3Y-TZP based dental restorations. J Eur Ceram Soc. 2012;32(10):2193-201. https://doi.org/10.1016/i.jeurceramsoc.2012.03.006

91. Ebert J, Ozkol E, Zeichner A, Uibel K, Weiss O, Koops $U$ et al. Direct inkjet printing of dental prostheses made of zirconia. J Dent Res. 2009;88(7):673-6. https://doi.org/10.1177/0022034509339988 